\title{
BCCM4
}

\section{INTEGRAL MANUFACTURING OF PLASTIC-METAL HYBRIDS CONSISTING OF ENDLESS FIBER REINFORCEMENT USING INJECTION MOLDING}

\author{
$\underline{\text { Tobias Gebken }}^{(1)}$, Markus Kühn(1), Michael Demes ${ }^{(1)}$, Anke Müller ${ }^{(1)}$ and Klaus \\ Dröder $^{(1)}$
}

(1) Technische Universität Braunschweig, Institute of Machine Tools and Production Technology, Braunschweig, Germany

https://doi.org/10.21452/bccm4.2018.07.02

\begin{abstract}
Injection molding is an economically attractive manufacturing process of short and long fiber-reinforced thermoplastic (TFRP) parts. The benefits in contrast to thermoset resin transfer molding (RTM) processes are the manufacturing of complex geometries in short cycle times. In the automotive sector, injection molding is one of the most common manufacturing processes for semi structural parts e.g. for the frontend, door coverings or functional joining parts.

In structural applications, the fiber specifications, volume content, length, material and orientation are influencing the characteristics of strength, stiffness and brittleness. Due to a nearly isotropic material behaviour of short TFRP parts, directional long or endless TFRP are suitable for a load path-oriented design. The load path oriented fibers lead to an anisotropic higher stiffness and strength. The integration of positioned long or endless fibers in the injection molding process and the realization of load transfer between metal and plastic are challenging tasks in present research works.

This paper deals with the integration of endless fibers in the injection molding process, focussing on the reinforced interface between metal and thermoplastic parts. The hybridization process and a calculation of the fiber infiltration time are presented. Furthermore, the performance of fiber-reinforced interfaces between metal and thermoplastic parts is characterized in tensile tests.
\end{abstract}




\section{INTRODUCTION}

Due to political restrictions of $\mathrm{CO}_{2}$ emissions, the automotive industry is required to manufacture fuel efficient vehicles [1]. A major factor is the vehicle mass, e.g. in car body structures [2]. By reducing the vehicle mass, the fuel consumption decreases and thus $\mathrm{CO}_{2}$ emissions are reduced as well. Therefore, new lightweight materials like fiber-reinforced plastics (FRP) and material combinations can be used to reduce vehicle's weight. However, integration of these new lightweight materials require highly efficient and economically advantageous manufacturing processes, compensating materials cost disadvantages. Current mid volume RTM processes, e.g. BMW's i3 with 17,000 vehicles per year (2014) [3], require long cycle times compared to manufacturing of conventional steel structures. Regarding FRP parts consisting of thermoset matrix, preforming, infiltration and curing take a significant amount of time. On the other hand, TFRP provide short cycle times suitable for automotive manufacturing processes as well as better recyclability.

Well-established manufacturing processes for thermoplastics and fiber-reinforced thermoplastics are thermoforming and injection molding technology. Thermoforming processes allow the manufacturing of large structures with long or endless fiber reinforcements but are restricted to flat geometries. In contrast, injection molding is qualified for large and geometrically complex parts with short and long fiber reinforcements while fiber lengths are limited to $3 \mathrm{~mm}$ due to polymer processing [4]. For structural or semi-structural parts, the fiber reinforcement is needed for higher strength, stiffness and impact strength [5]. Towards load path and lightweight designed FRP, it is necessary to integrate endless fiber reinforcements in load path orientation. The density of glass fibers $\left(\sim 2.5 \mathrm{~g} / \mathrm{cm}^{3}\right)$ is higher by a factor of $>2$ compared to polyamide $6\left(\sim 1.1 \mathrm{~g} / \mathrm{cm}^{3}\right)$. Therefore, a local fiber reinforcement is a promising approach to avoid a high fiber volume content in part areas, where fibers are not needed [6, 7].

This paper deals with the integration of endless fibers in the interface of a metal and plastic structure. For fiber integration, an interface design is presented as well as a simulation to calculate the infiltration time subjected to the melt pressure and viscosity. The manufactured specimens with a fiber-reinforced interface are characterized in a tensile test. The overall bond strength is benchmarked with a conventional short fiber-reinforced thermoplast.

\section{EXPERIMENTAL SETUP}

\subsection{Design}

In vehicle structures, multimaterial design methods are increasingly pursued to create functional integration as well as weight reduction. In plastic-metal hybrid car structures, plastic-metal interface is a highly stressed transition zone where failures often occur by early cracks. For the design of high performance interfaces, mechanical interlocking and adhesive bonding are used. Therefore, mechanical undercuts [8] or a laser structuring on metal surfaces [9] are common processes. For the material bond adhesive promoters are used [10].

To improve the material interface strength and avoid an early crack in the interface area by a flank tensile crack, a fiber loop reinforcement in load path direction is pursued. The fiber loops are integrated in the injection molding die and embedded in the thermoplastic part. By using the flow direction of the melt, the fibers are positioned. The fiber loop reinforcements introduce the load directly from the metal into the thermoplastic material. Thereby, the interface zone is not limited to the metal surface area.

\subsection{Process setup and test specimen}

Figure 1 shows the experimental process chain for the manufacturing of hybrid TFRP with an endless fiber reinforcement in the interface zone. The process contains a pre-coating step 
for the application of an adhesive promoter. For a homogeneous thickness of the adhesive promoter, its application is performed with an electrical potential between adhesive promoter and metal part. The second step is the draping and fixation of the fibers around the metal as a loop. This process is performed at a minimum temperature of $165^{\circ} \mathrm{C}$ to activate the adhesive promoter [11] and fixate the fiber. Injection molding is used for integral joining and forming.
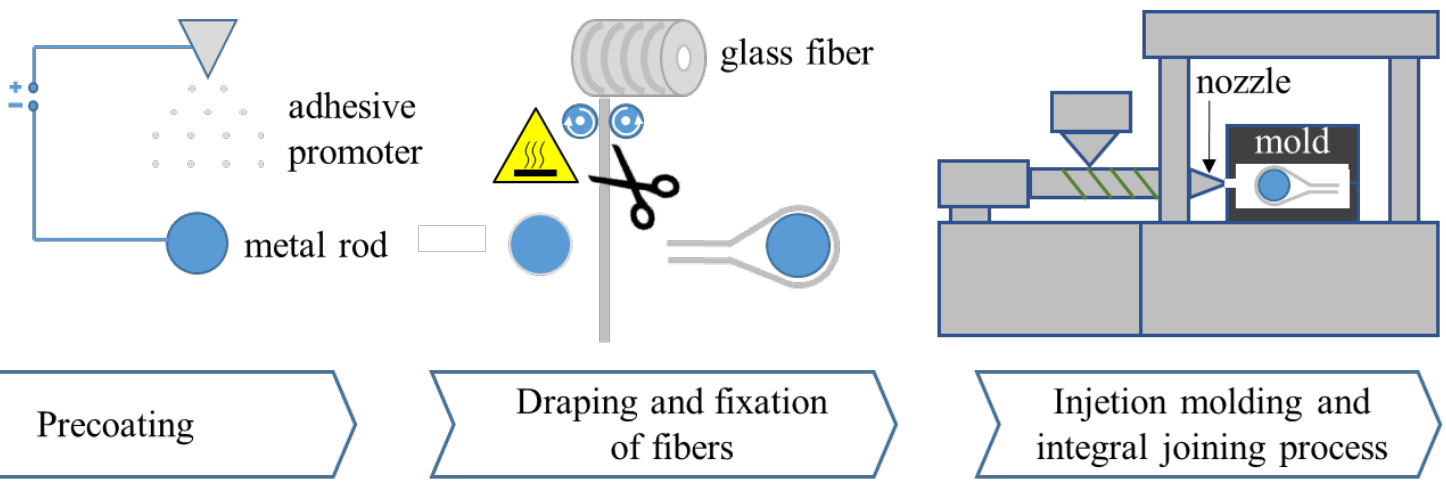

Figure 1: Process chain with endless fiber reinforcement in TFRP

In this paper, an injection mold is set up to manufacture an endless fiber-reinforced material interface between metal and thermoplastic material. The geometry of the specimens is shown in Figure 2. A metal rod with a diameter of $6 \mathrm{~mm}$ and a polymeric form with thicknesses between $4.0 \mathrm{~mm}$ and $7.2 \mathrm{~mm}$ are designed. The specimen depth is $20.0 \mathrm{~mm}$.

PA6 specimen

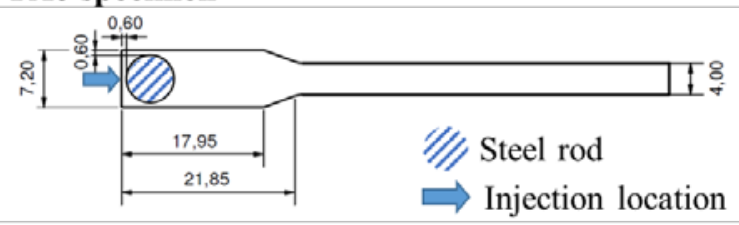

PA6 with endless fiber

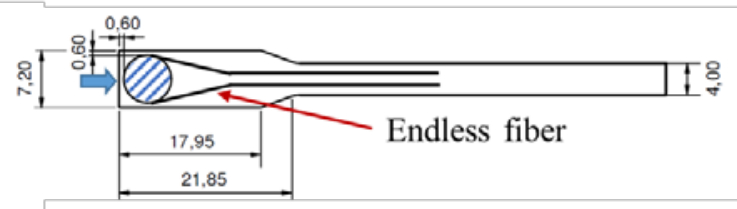

Figure 2: Geometry of the test specimen: Metal-PA6 (left), Metal-PA6 with fiber reinforcement (right)

\subsection{Materials}

The experiments are performed with the materials shown in Table 1 . The inserts consist of a steel rod of $11 \mathrm{SMn} 30+\mathrm{C}$ and an electric glass fiber with 1,200 tex per roving. The fiber filaments have a diameter of approximately $16 \mu \mathrm{m}$. An easy flowing polyamide 6 (PA 6) is used without filling fibers as well as with a glass fiber volume content of $30 \%$. The short fiber-reinforced PA 6 is used during the experiments for benchmark reasons.

Table 1: Materials

\begin{tabular}{ccc}
\hline & Type & Fiber content \\
\hline Fiber & E-glass & 1,200 tex \\
Polymer & PA 6 & 0 vol.\% / 30 vol.\% \\
Steel & 11SMn30+C & - \\
\hline
\end{tabular}

\section{PROCESS SIMULATION}

\subsection{Theoretical approach}

The infiltration and consolidation of endless fibers in an injection molding process is an important step for a good matrix-fiber load transmission. Therefore, many efforts deal with the theoretical and numerical calculation of the degree of infiltration. In this work, the degree 
of infiltration is calculated with a theoretical approach, whereas the major variables are simulated. The degree of infiltration is shown in dependence of the number of fiber layers as well as the melt pressure in the mold.

The analytical approach towards the fiber bundle infiltration with one flow front $[12,13]$ is shown in equation 1 . Here, $t_{\text {micro }}$ represents the micro-infiltration time, $\eta$ the viscosity, $p$ the infiltration pressure. The ratio of the eccentricity $x$ is calculated with $x=\frac{2-\lambda}{\lambda^{2}+1}$ with $\lambda=\frac{a}{b}$. The fiber bundle radius $r_{f b}$ is calculated with equation 2 .

$$
\boldsymbol{t}_{\text {micro }}=\frac{1}{4} \cdot \frac{\eta \cdot\left(1-\varphi_{\text {micro }}\right) \cdot r_{f b}{ }^{2} \cdot x}{s \cdot p} \quad \text { (1) with } \quad r_{f b}=\sqrt{\frac{t e x}{\pi \cdot \rho_{f i l} \cdot \varphi_{\text {micro }}}}=\mathbf{0 . 4 7} \mathbf{m m}
$$

Table 2: Fiber textile parameter

\begin{tabular}{cc}
\hline Parameter & Value \\
\hline Fiber volume content $\varphi_{\text {micro }}$ & $0.7[-]$ \\
Permeability $S$ & $9.2 \cdot 10^{-14}\left[\mathrm{~m}^{2}\right]$ \\
Fiber bundle spread $a$ & $5[\mathrm{~mm}]$ \\
Fiber bundle thickness $b$ & 0.25 and $1[\mathrm{~mm}]$ \\
Fiber tex & $1,200\left[\frac{\mathrm{g}}{\mathrm{km}}\right]$ \\
Filament density $\rho_{\text {fil }}$ & $2.5\left[\frac{\mathrm{g}}{\mathrm{cm}^{\mathrm{a}}}\right]$
\end{tabular}

The presented parameters in Table 2 are specific characteristics of the fiber textile. The process dependent parameters are the pressure $p$ and the melt viscosity $\eta$. These parameters can be evaluated in experiments or can be simulated in an injection molding simulation. In this work, a study with a parameter variation is performed to investigate the influence of varying pressure profiles on the infiltration behavior. Furthermore, two different numbers of fiber layers are taken into account.

\subsection{Injection molding}

The injection molding simulation is performed by using the software Moldflow ${ }^{\circledR}$. In Figure 3 the temperature distribution is shown for three different time steps. In the first time step at $0.4906 \mathrm{~s}$, the compression phase is completed, whereas the second time step at $2.491 \mathrm{~s}$ is during the holding pressure. At the last time step at $5.485 \mathrm{~s}$, the holding pressure is finished and the cooling phase starts. The core temperature of the melt during the compression and holding pressure phase balances around $261^{\circ} \mathrm{C}$. This value is validated by experiments with $258{ }^{\circ} \mathrm{C}$ melt temperature in the core. Heat transfer in the gating system can explain the temperature deviation of $3{ }^{\circ} \mathrm{C}$. Furthermore, the decreasing temperature from the tool surface to the core is shown in Figure 3. A fiber placement with respect to the fiber infiltration is only suitable in the high temperature core. The resultant viscosity and pressure profile at the point of measuring is shown in Figure 4. 


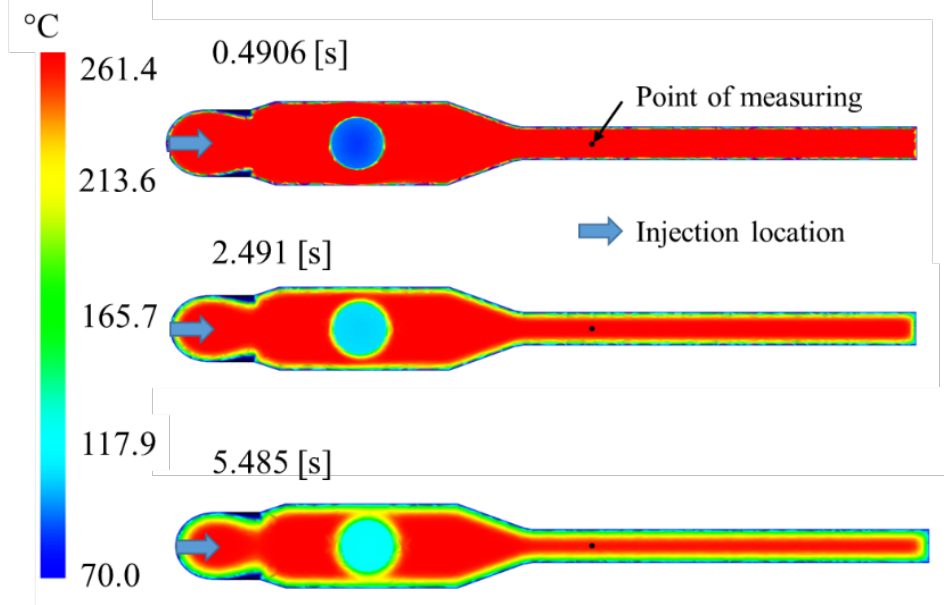

Figure 3: Simulation of specimen temperature during the injection molding process for a low pressure profile

\subsection{Study of process parameters}

The following study contains a time dependent simulation of the melt pressure and the melt viscosity. Therefore, three different pressure profiles are taken into account. For the pressure profiles an injection step, a compression step, a holding pressure step and a cooling step are characteristic. In Figure 4 a low, middle and high pressure profile is taken into account. In addition, the viscosity profiles are shown up for the different pressure profiles. The results show that the viscosity is nearly non-affected by the pressure. However, the results in Figure 3 and Figure 4 show an increasing viscosity with increasing time. During the cooling phase ( $>$ $6 \mathrm{~s})$ the thermoplastic viscosity increases into solidification. With the time dependent pressure and viscosity, it is possible to calculate the total micro infiltration time $t_{\text {micro }}$ with equation 1 . Therefore, a total equation is needed to calculate the "degree of infiltration" considering $I_{\text {fin }}$ the micro infiltration time as a function of the simulated time steps. The total equation is shown in equation 3.

$I_{f i l}=\sum_{i=1}^{t_{n}} \frac{t_{\text {step }, i}-t_{\text {step }, i-1}}{t_{\text {micro }, i}}$

In Figure 4, the degree of infiltration $I_{\text {fi }}$ is diagramed as a function of fiber textile layers (1 layer and 4 layers) as well as three different pressure profiles (low, middle, high). The results are calculated for a one-side fiber infiltration and a non-varying textile temperature.

The results show that the infiltration of the 1 layer and 4 layers textiles with a high and middle pressure profile is completed during the compression phase. The infiltration degree of the 1 layer with low pressure is completed during the holding pressure phase, whereas the 4 layer textile with the low pressure profile could not be completely infiltrated during the holding pressure phase (Figure 4). This textile only reaches an infiltration value of $50 \%$. 


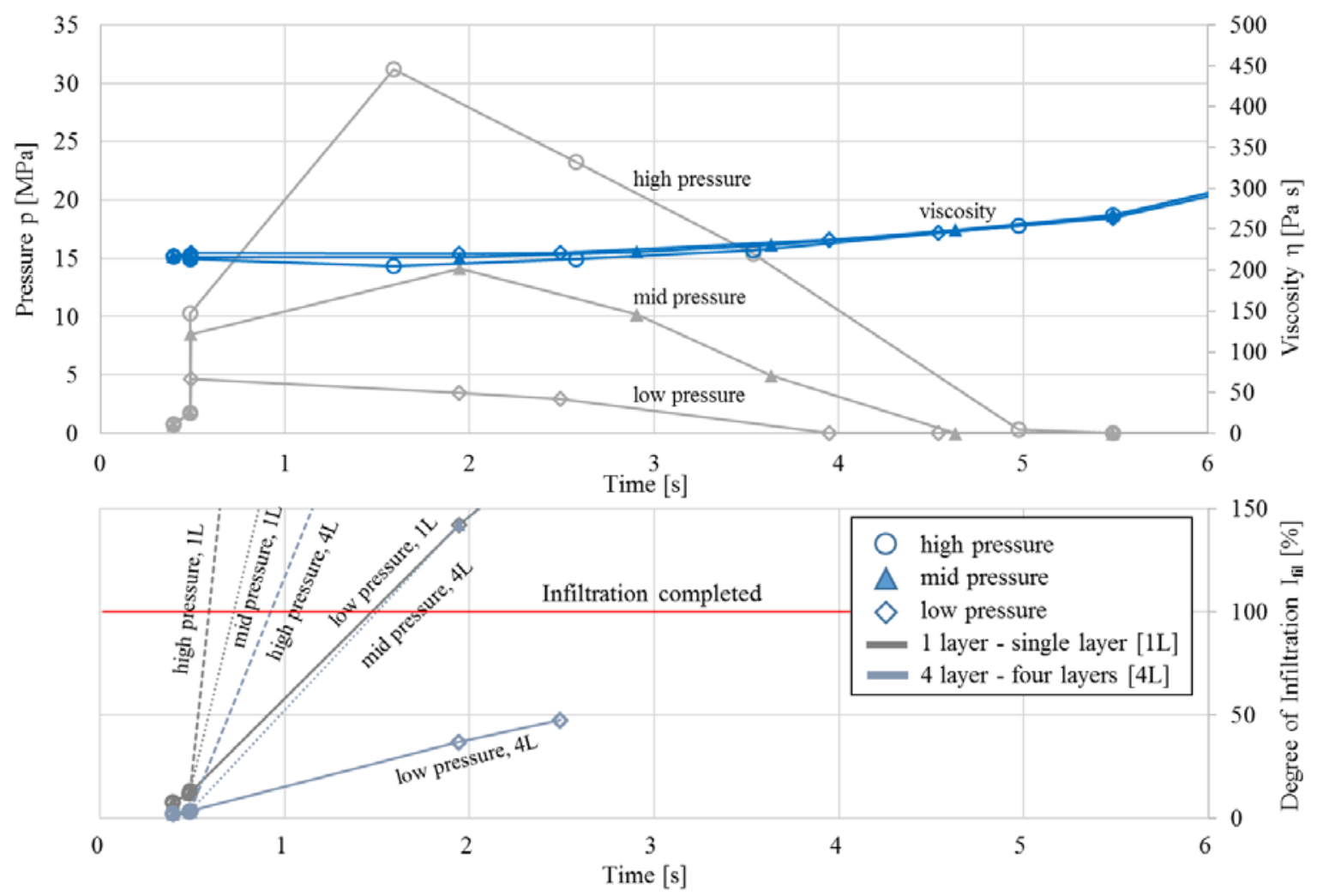

Figure 4: Calculated parameters; process pressure and viscosity (top); degree of infiltration calculated with equation (3) (bottom)

By using this co-calculation strategy between the analytical and numerical approach, it is possible to take varying process parameters for the calculation of infiltration degrees into account. Thus, a time and cost efficient process for the design of fiber reinforcements in the injection molding process can be performed.

\section{TESTING}

To investigate the bond strengths of plastic-metal interfaces using continous fiber loops for reinforcement, test specimens (Figure 2) are manufactured through injection molding. The benchmark is performed with a short glass fiber reinforced specimen. The parameter variation consists of a PA 6 specimen with no fiber reinforcement as well as a 1- and 2-fiber loop reinforcement. The metal inserts are placed into the mold at ambient temperature of $20^{\circ} \mathrm{C}$ and a pre-heated mold temperature of $270^{\circ} \mathrm{C}$. During insert preparation and the dwell time in the mold, the mold temperature of $70^{\circ} \mathrm{C}$ affects the metal rod temperature. Thereby, the temperature of the metal rod is increased from $20^{\circ} \mathrm{C}$ to $50^{\circ} \mathrm{C}$ and decreased from $270{ }^{\circ} \mathrm{C}$ to $200^{\circ} \mathrm{C}$. The manufactured specimens are tested with a testing speed of $5 \mathrm{~mm} / \mathrm{min}$ in a tensile test with a predicted crack at the specimen flank.

The results of the investigation are shown in Figure 5. A non-reinforced PA 6 reaches a tensile load of $2.1 \mathrm{kN}$. The load can be increased to $2.9 \mathrm{kN}$ with 1 fiber loop and to $3.9 \mathrm{kN}$ with 2 fiber loops. The benchmark was performed with a 30 vol.\% glass-fiber reinforced PA 6, which reaches a tensile load of $3.7 \mathrm{kN}$. The fiber volume contents of the single fiber loop and double fiber loop reinforced material flank can be calculate to $10 \mathrm{vol} \%$ and 20 vol.\%. 


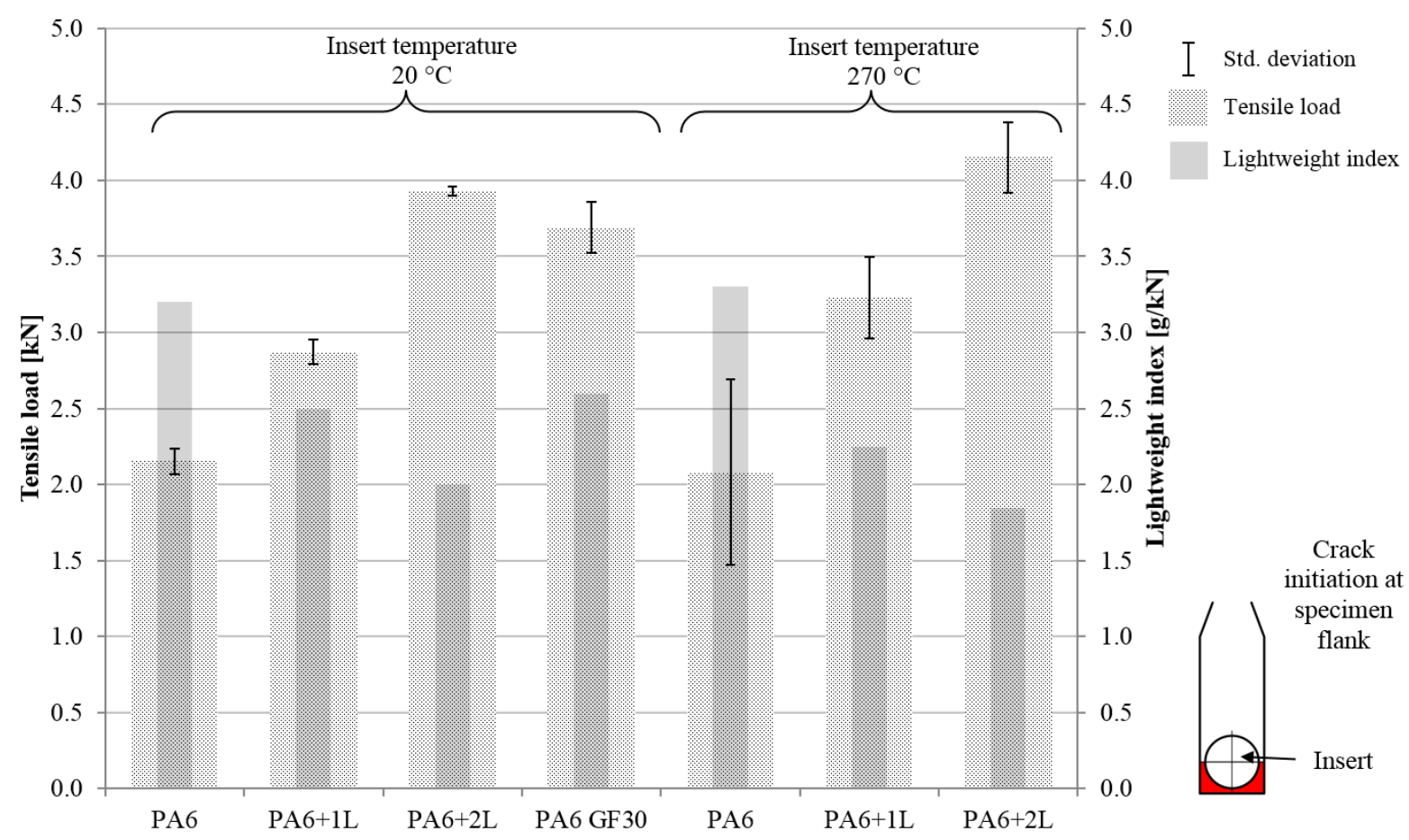

Figure 5: Results of tensile testing and failure behavior

In Figure 5 the relation between weight and tensile load is considered in the lightweight index. The results show, that the lightweight index for the fiber loop reinforced material interface is $2.5 \mathrm{~g} / \mathrm{kN}$ and $2.0 \mathrm{~g} / \mathrm{kN}$, whereas the benchmark (PA6 GF30) reaches $2.6 \mathrm{~g} / \mathrm{kN}$. Furthermore, the preheated metal rods $\left(270^{\circ} \mathrm{C}\right)$ result in higher tensile loads, especially for the specimens with a fiber textile loop reinforcement. However, the results of the pre-heated metal rod inserts show a higher standard deviation, which can be caused in a temperature deviation of the metal inserts. Due to the higher metal insert temperature the infiltration of the textile is favored. Thus, a higher fiber matrix infiltration can be reached and lead to higher tensile loads.

\section{SUMMARY AND OUTLOOK}

In this work, a concept for a material interface between metal and a thermoplastic with higher performance is demonstrated. The performance improvement is reached through an endless fiber loop reinforcement. The process compatibility of fibers in the injection molding process is verified. By using the direction of the melt flow, a directional fiber orientation is achieved. Furthermore, a numerical approach to evaluate time dependent process parameters from the injection molding process is performed. The parameters are used for the analytical calculation of the fiber infiltration. The improvement of the fiber loops in the material interface are shown by the results of the tensile tests. Moreover, heated metal inserts are improving the fiber infiltration with thermoplastic melt, which leads to higher possible tensile loads. In further investigations, a parameter study by varying the metal insert temperature will be on focus. As well, an experimental validation of the infiltration calculation will be performed by using graphical microsection analysis. 


\section{REFERENCES}

[1] Goede, M., (2007) Karosserieleichtbau als Baustein einer CO2-Reduzierungsstrategie, 16. Aachener Kolloquium Fahrzeug und Motorentechnik, Aachen

[2] Davies, G., (2012) Materials for Automobile Bodies, Second Edition, Butterworth-Heinemann, Oxford

[3] Pandow, G., (2016) IHS-Prognose: BMW-i3-Absatz wird sich verdoppeln, Automobil Produktion, Landsberg

[4] Faruk, O., (2012) Biocomposites reinforced with natural fibers: 2000-2010, Journal Progress in Polymer Science 37, Toronto, p. 1552-1596

[5] Thomason, J.L., (2002) The influence of fibre length and concentration on the properties of glass fibre reinforced polypropylene: 5. Injection moulded long and short fibre PP. In: Composites: Part A 33, p. 1641 - 1652

[6] Tröltzsch, J., (2011) Entwicklungen zur partiellen Verstärkung von thermoplastischen Spritzgießbauteilen, Abschlussseminar PAFATHERM, TU Chemnitz

[7] Gebken, T., Seemann, T., (2016) Prozessentwicklung für den hybriden Leichtbau am Beispiel einer endlosfaserverstärkten Aluminium-FVK-Struktur, Symposium Hybrider Leichtbau, its automotive nord, Braunschweig

[8] Dröder, K., Brand, M., Gebken, T., Kühn, M., Böl, M., (2016) Increasing the interlocking effect between metal and FRP by mechanical undercuts, Int. J. Automotive Composites, Vol. 2, Nos. $3 / 4$

[9] Kahmann, M., Quentin, U., Kirchhoff, M., Brockmann, R., Löffler, K., (2015) Laser based surface structuring for lightweight design, Lasers in Manufacturing Conference

[10] Aßmann, K., Locher, A., (2014) elements 48, Quarterly Science Newsletter, Issue 3, Evonik Industries AG, Essen, pp. 6-11.

[11] Demes, M., Weimer, J., Kühn, M., Kreling, S., Dröder, K.; Dilger, K., (2017) Creating polymer metal hybrids of hot stamped steel and fiber-reinforced thermoplastics using residual process heat, SAMPE Conference Proceedings. Seattle, WA

[12] Ehleben, M., (2002) Herstellung von endlosfaserverstärkten Rohren mit thermoplastischer Matrix im Schleuderverfahren, Dissertation, Shaker Verlag, Aachen

[13] Gebken, T., Kühn, M., Dröder, K., (2017) Integration of endless fibres in the injection moulding process, SAMPE Europe Conference, Stuttgart, Germany 